\title{
Dados de gravimetria por satélite aplicados à exploração mineral
}

\author{
Denis K. S. Barbosa, Eder C. Molina, IAG-USP
}

Copyright 2016, SBGf - Sociedade Brasileira de Geofísica

Este texto foi preparado para a apresentação no VII Simpósio Brasileiro de Geofísica Ouro Preto, 25 a 27 de outubro de 2016. Seu conteúdo foi revisado pelo Comite Técnico do VII SimBGf, mas não necessariamente representa a opinião da SBGf ou de seus associados. É proibida a reprodução total ou parcial deste material para propósitos comerciais sem prévia autorização da SBGf.

\section{Resumo}

The GOCE satellite has greatly improved gravimetric researches about the structure of the Earth. Recent published works shown that these data can also be used aiming mineral exploration. These works show that the residual Bouguer anomaly, processed from satellite data, can give information about the direction, orientation and/or the main regions that must be studied in detail: this is the case for Carajás, Alta Floresta and Quadrilatero Ferrifero mineral provinces, studied in this work. On the other hand, Tapajos mineral province, however, shows no apparent relation to the residual Bouguer anomaly. It is expected that the conclusions of this work can help to reduce the costs of projects using airbone surveys and the mineral exploration process.

\section{Introdução}

O uso dos dados de gravimetria por satélite ganha cada vez mais importância pelo avanço tecnológico na aquisição e no processamento das informações, além da gratuidade de acesso aos dados, que podem ser adquiridos pelo Calculation Service do site do ICGEM (International Center for Global Gravity Field Models). Este serviço permite o acesso a modelos que utilizam os dados dos diversos satélites de aquisição das últimas três décadas, sendo o mais recente o GOCE (Gravity Field and Steady-State Ocean Circulation Explorer), cujo lançamento ocorreu em 2009.

Dentre as recentes aplicações deste tipo de dado está o auxílio à exploração mineral, a exemplo de Braitenberg (2015), que identificou possíveis direções e configurações de depósitos auríferos do Zimbábue, orientando deste modo novas explorações mais detalhadas com aeromagnetometria e aerogravimetria.

Esta conclusão para o Zimbábue inspira a aplicação da técnica em outros países. No presente trabalho estudarse-á o Brasil que, segundo o IBRAM (Instituto Brasileiro de Mineração), possui menos que $30 \%$ de seu território explorável (IBRAM, 2013) coberto por levantamentos geológicos. Mesmo com essa pequena percentagem pesquisada, o Brasil tem um papel chave na produção de minerais metálicos no mundo: é líder na produção de nióbio; segundo colocado na produção de ferro; terceiro colocado na produção de alumínio, e outras posições e produtos de destaque.

Sob a perspectiva de pouco investimentos em exploração mineral no Brasil, embora este seja um dos maiores exportadores destes bens, a gravimetria por satélite se mostra como uma ferramenta com excelente potencial para determinar áreas de maior interesse exploratório, guiando futuras pesquisas e almejando a eficácia e eficiência dos investimentos já escassos.

Os dados a serem estudados correspondem a boa parcela da América do Sul, abrangendo e focando-se apenas no Brasil. Serão estudadas em detalhe quatro províncias minerais brasileiras, a saber: Carajás, Tapajós, Alta Floresta e Quadrilátero Ferrífero, haja vista a importância e produtividade destas.

\section{Metodologia}

A metodologia aplicada segue o mesmo procedimento de Braitenberg (2015): em primeiro lugar é realizado o download dos dados de topografia e anomalia Bouguer do Calculation Service do ICGEM; em seguida, aplica-se o conceito de topografia equivalente aos dados de topografia, processo pelo qual se iguala o efeito isostático de uma coluna d'água por uma coluna de crosta oceânica, conforme equação 1 , onde $\rho_{c}=2,670 \mathrm{~g} / \mathrm{cm}^{3}$ e $\rho_{\mathrm{w}}=1,040 \mathrm{~g} / \mathrm{cm}^{3}$.

$$
\text { Topo }_{\text {equiv }}=\left\{\begin{array}{l}
\text { topografia, se topografia } \geq 0 \\
\text { topografia }\left(\frac{\rho_{c}-\rho_{w}}{\rho_{c}}\right), \text { se topografia }<0
\end{array}\right.
$$

O próximo passo consiste na relação da anomalia Bouguer com a deflexão da descontinuidade Moho dada pela equação 2 , que relaciona a deflexão $\mathrm{w}$ em unidades métricas, a força lateral $F$, a força vertical por unidade de área $\mathrm{q}(\mathrm{x})$ e a rigidez flexural $\mathrm{D}$. Resolvendo-a, obtém-se a equação da anomalia Bouguer para a porção deflexionada (raíz) da crosta continental (equação 3).

$$
\begin{aligned}
& D \frac{d^{4} w}{d x^{4}}+F \frac{d^{2} w}{d x^{2}}=q(x) \\
& \Delta g_{\text {Braiz }}=-2 \pi G \rho_{c} \text { Topo } o_{\text {equiv }}
\end{aligned}
$$

A partir da equação 3 pode-se remover o efeito isostático da região das províncias minerais. Destaca-se também o fato de a equação 3 ser semelhante a uma equação de primeiro grau sem coeficiente linear. Aplica-se então o Método dos Mínimos Quadrados (MMQ) para os dados de anomalia Bouguer em função dos dados de topografia equivalente. $O$ residual deste ajuste será considerado como resultante da geologia local, sendo, portanto, o dado a ser interpretado. 


\section{Resultados}

Primeiramente há a necessidade de observar-se a qualidade e adequação do ajuste realizado. A Figura 1 demonstra os dados de anomalia Bouguer em função dos dados de topografia equivalente para a América do Sul, mais precisamente no quadrante de latitude $10^{\circ} \mathrm{N}$ a $36^{\circ} \mathrm{S}$ e longitude $-80^{\circ} \mathrm{W}$ a $-30^{\circ} \mathrm{W}$. Tabela 1 relata os parâmetros adquiridos pelo $\mathrm{MMQ}$.

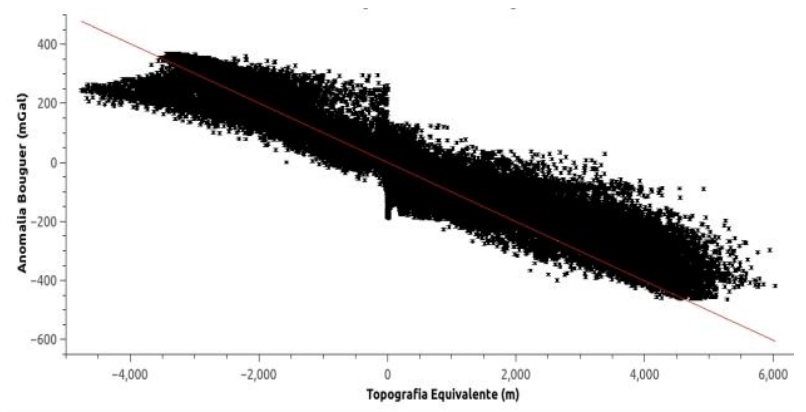

Figura 1 - Ajuste pelo MMQ dos dados de anomalia Bouguer em função dos dados de topografia equivalente.

Tabela 1: Parâmetros adquiridos pelo ajuste por MMQ da Figura 1.

\begin{tabular}{|c|c|}
\hline Parâmetro & Valor obtido \\
\hline $\mathbf{A}(\mathbf{m G a l} / \mathbf{m})$ & $-0,10043(49)$ \\
\hline $\mathbf{R}^{\mathbf{2}}$ & 0,940 \\
\hline
\end{tabular}

O mapa contendo o residual deste ajuste, considerado como resultante da geologia local, é denominado de Mapa Residual da Anomalia Bouguer e é apresentado na Figura 2 juntamente com os contornos das províncias minerais brasileiras conforme Dardenne \& Schobbenhaus (2003).

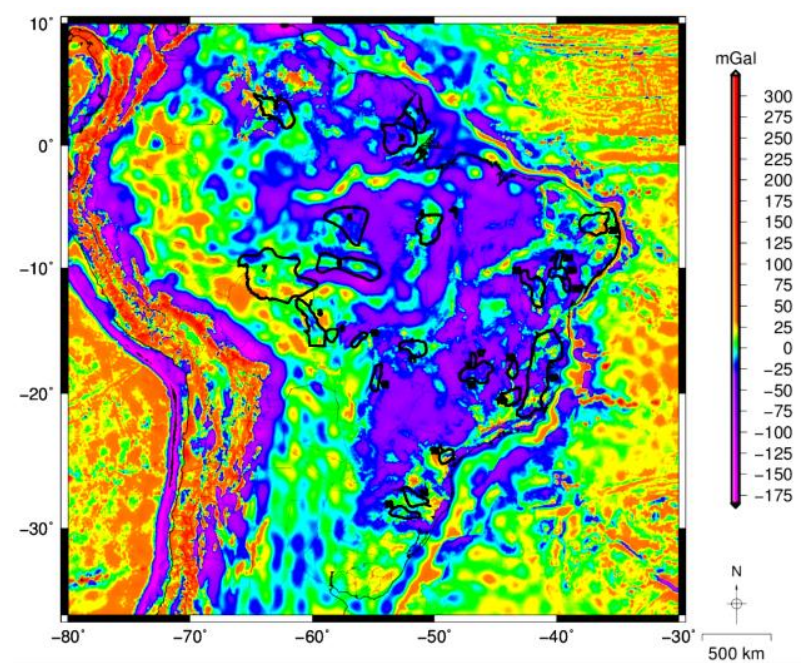

Figura 2 - Mapa de Residual da Anomalia Bouguer para $o$ ajuste mostrado na Figura 1. Os contornos correspondem às províncias minerais brasileiras apresentadas em Dardenne \& Schobbenhaus (2003).
De um modo geral, as províncias estão associadas aos altos residuais. Porém, um estudo em detalhe é necessário para todas as províncias nas quais, a exemplo de Braitenberg (2015), estão apresentados os locais de exploração atual ou abandonadas. As Figuras $3,4,5$ e 6 ilustram os mapas residuais de anomalia Bouguer para as províncias de Tapajós, Carajás, Alta Floresta e Quadrilátero Ferrífero.

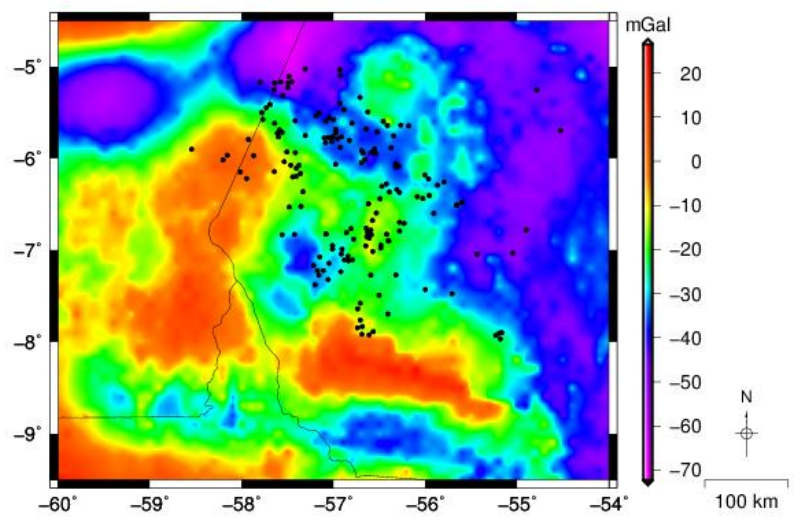

Figura 3 - Residual da Anomalia Bouguer para a região da província de Tapajós. Os pontos correspondem à localização das minas exploratórias da província.

A província de Tapajós é a maior produtora de ouro do Brasil. Nela há depósitos associados com: zonas de cisalhamento, com produções de até $32 \mathrm{~g} / \mathrm{t}$ Au e média de 9,3 g/t Au; intrusões, via preenchimento de fraturas e em seus arredores; e de paleoplacer predominantes (Dardenne \& Schobbenhaus, 2001).

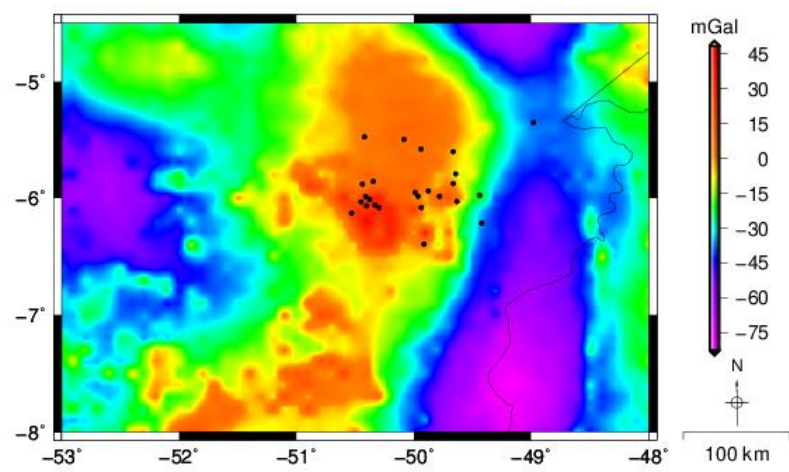

Figura 4 - Residual da Anomalia Bouguer para a região da província de Carajás. Os pontos correspondem à localização das minas exploratórias da província.

A província de Carajás está entre as maiores produtoras de ferro do Brasil, produzindo também manganês, ouro, cobre e níquel. É característica do Neo-Arqueano (2,8 a 2,5 Ga) e seus minérios, a grosso modo, são de origem metamórfica - ouro em zonas de cisalhamento, por exemplo -, sedimentar - lixiviação, que gerou uma crosta de ferro e alumínio -, e magmática - intrusões com ETR, $\mathrm{Cu}, \mathrm{Au}$ e U (Dardenne \& Schobbenhaus, 2003). 


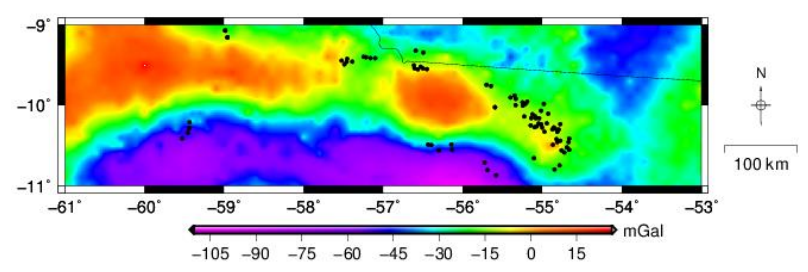

Figura 5 - Residual da Anomalia Bouguer para a região da província de Alta Floresta. Os pontos correspondem à localização das minas exploratórias da província.

A província Alta Floresta é produtora de ouro, zinco, chumbo e cobre, sendo o primeiro o mais importante. $\mathrm{O}$ ouro é amplamente distribuído, havendo aqueles associados a zonas de cisalhamento e estruturas extensionais, a alterações hidrotermais e intrusões controladas por lineamentos regionais ou zonas de cisalhamento (Dardenne \& Schobbenhaus, 2003).

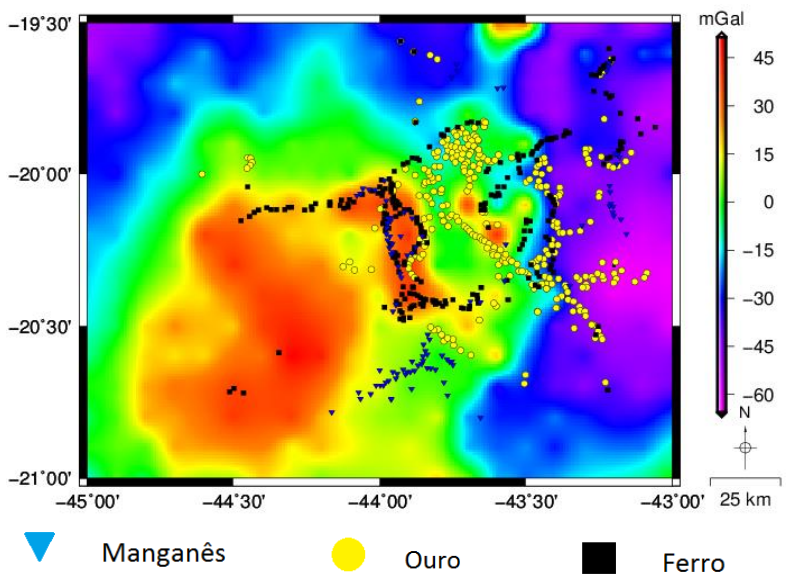

Figura 6 - Residual da Anomalia Bouguer para a região da província do Quadrilátero Ferrífero. Os pontos correspondem à localização das minas exploratórias da província: preto correspondem às minas de ferro; azul às de manganês e amarelo às de ouro.

A província do Quadrilátero Ferrífero é, sem sombra de dúvidas, a de maior relevância cultural e histórica para o nosso país. Há inúmeros estudos nesta província, de gênese e evolução complexas.

Os depósitos encontrados são de manganês, ferro e ouro, de gênese a partir do Arqueano. São depósitos de origem metamórfica, magmática, hidrotermal e sedimentar, que geralmente passaram por mais de um desses processos.

Esta é a única província em que foi possível adquirir a localização das minas conforme o mineral que produzem devido ao maior número de estudos e de maior publicidade destes, enriquecendo a interpretação.

Os depósitos de ouro estão associados ao Grupo Nova Lima - unidade basal da província - que, segundo Vieira \& Oliveira (1988) passou por metamorfismo de baixo e médio graus e processo mineralizador hidrotermal, sendo que 0 primeiro gerou zonas de cisalhamento acompanhadas de intensa alteração hidrotermal. processo citado ocorre preferencialmente por substituição ao longo de formações ferríferas bandadas (FONTE).

\section{Discussão e Conclusões}

A adequação da teoria se mostrou perfeitamente válida, conforme ilustram a Figura 1 e Tabela 1: o coeficiente de correlação $\mathrm{R}^{2}$ apresenta um valor próximo de 1 , conferindo validade ao ajuste linear utilizado (aquele apenas com o coeficiente angular).

Comprovada esta etapa, segue-se a interpretação dos mapas de residuais da anomalia Bouguer. De um modo geral, as províncias definidas por Dardenne \& Schobbenhaus (2003) coincidem com os altos residuais, que por sua vez correspondem aos escudos cristalinos do território sul-americano que são, por natureza, mais densos.

A representação dos dados de localização das minas para cada província resulta nas Figuras 3, 4, 5 e 6 para as províncias de Tapajós, Carajás, Alta Floresta e Quadrilátero Ferrífero, respectivamente.

Para a província de Tapajós não há uma correlação clara para a localização das minas com os altos anômalos. Este resultado condiz com a distribuição ampla de intrusões e da forte predominância de depósitos minerais com influência sedimentar (paleoplacers) que não têm uma tendência de concentração de minerais mais pesados e, por isso, não apresentam altos anômalos no mapa de residual da anomalia Bouguer. Contudo, o alto anômalo a oeste da província apresenta minas e, por isso, deve ser um alvo de interesse futuro na exploração em detalhe.

A província de Carajás (Figura 4), por sua vez, apresenta um alto residual que se correlaciona com quase a totalidade das minas da província. Por este motivo, sugere-se que 0 alto residual deve ter suas bordas melhor exploradas, incluindo-se na futura pesquisa exploratória o alto residual mais ao sul.

A Figura 5 ilustra o residual da anomalia Bouguer para a província de Alta Floresta. Nesta é possível destacar, observando-se apenas a localização das minas, a tendência linear destas, decorrente das zonas de cisalhamento.

Unidas ao mapa de residual da anomalia Bouguer para a província, as minas apresentam-se nas bordas de um alto residual, sendo este interpretado como uma possível zona de cisalhamento de alto ângulo com possíveis depósitos minerais e, portanto, de interesse exploratório em pesquisas futuras.

A província do Quadrilátero Ferrífero (Figura 6) é a de maior densidade de minas. Observando-se apenas as minas constata-se que há lineamentos SW-NE para minas com produção de ferro e manganês, N-S para ferro e SE-NW para depósitos de ouro. Estes lineamentos são interpretados como correspondentes a depósitos que se concentram em zonas de cisalhamento (ferro e ouro). Colocando em um mesmo mapa a anomalia residual e as minas observa-se que estas estão, assim como ocorre na província Alta Floresta, próximas aos altos residuais, que 
podem ser igualmente interpretados como zonas de cisalhamento de alto ângulo.

Com base nesta interpretação, sugere-se que trabalhos futuros devam concentrar suas forças nestes altos, principalmente no alto residual a oeste, que apresenta algumas minas no centro do alto e em sua borda norte.

De modo geral, apenas utilizado os dados de gravimetria por satélite do GOCE - de acesso gratuito -, é possível sugerir regiões de maior interesse exploratório para as províncias minerais de Tapajós, Carajás, Alta Floresta e Quadrilátero Ferrífero apenas sabendo a posição da exploração (atual e pretérita) e aplicando técnicas de remoção do efeito isostático. Pesquisas como esta se mostram de extrema importância para o Brasil, conferindo maior eficiência nos gastos exploratórios minerais.

\section{Agradecimentos}

Agradeço imensamente ao CNPq pela oportunidade da bolsa de mestrado, à professora Carla Braitenberg e ao Tommaso Pivetta, ambos da Università degli Studi di Trieste, pela paciência em sanar minhas dúvidas e na prontidão das respostas.

É impossível esquecer de agradecer ao corpo docente e administrativo do Instituto de Astronomia, Geofísica e Ciências Atmosféricas da Universidade de São Paulo (IAG-USP) por me acolher desde a graduação e responder-me sempre com cortesia e educação.

\section{Referências}

Azevedo, U. R. et al. (05 co-autores), 2012. Geoparque Quadrilátero Ferrífero (MG). In: Schobbenhaus, C., Silva, C. R. da (org.), Geoparques do Brasil. V. 1: 183-220. Brasília, DF, Brasil.

Biondi, J. C., 2003. Processo metalogenéticos e os depósitos minerais brasileiros. Oficina de Textos, $1^{\text {a }}$ ed., São Paulo, SP, Brasil.

Braitenberg, C., 2015. Exploration of tectonic structures with GOCE in Africa and across-continents. Int. J. Appl. Earth Observ. Geoinf. Vol. 35A: 88-95.

Dardenne, M.A., Schobbenhaus, C., 2001. Metalogênese do Brasil, Editora UnB, Brasília, DF, Brasil.

Dardenne, M. A., Schobbenhaus, C., 2003. Depósitos minerais no tempo geológico e épocas metalogenéticas (Mineral depositos in Brazil: distribution in time, provinces and metallogenic epochs). In: Bizzi, L. A., Schobbenhaus, C., Vidotti, R. M., Gonçalves, J.H. (Coord.) Geologia, Tectônica e Recursos Minerais do Brasil. Brasília, DF, Brasil. 365-448.

Turcotte, D. L., Schubert, G., 2010. Geodynamics, Cambridge University Press, 2nd ed., Los Angeles, California, USA.
Vieira, F. W. R., Oliveira, G. A. I. de. Geologia do distrito aurífero de Nova Lima, Minas Gerais. In: Schobbenhaus, C.; Coelho, C. E. S. (Coord.). Principais depósitos minerais do Brasil: ferro e metais da indústria do aço. Brasília, DF, Brasil. V. 3: 377-391. 